\title{
Social Responsibility in Sports: A Call for a Systematic Approach
}

\begin{abstract}
Jason Chung*
There appears to be a general understanding among stakeholders in the sports industry that its organizations have a distinct responsibility to engage in socially responsible behavior and works. This has resulted in a plethora of types of activities undertaken as part of this social responsibility of sports (SRS). However, efforts to measure and systematize SRS activities to gauge effectiveness and impact have proven to be a challenge. Much as with corporate social responsibility efforts in other industries, the sheer breadth and diversity of motives and modes of engagement for SRS activities often obfuscate goals and metrics for success. This paper outlines such challenges and provides a framework for engaging in SRS in a manner that advances both organizational and societal goals. It also argues that the desire to "do good" among sports organizations must be complemented by a systematic approach and consistent program evaluation using mixed methodological methods to maximize the impact of SRS dollars. Should the sports industry be able to agree and commit to such an approach, it can serve as an example for responsible and effective social engagement to other industries.
\end{abstract}

\section{Introduction}

Due to the expansive nature of what is captured by activities performed under the social responsibility of sports (hereafter SRS), systematizing and measuring outcomes of such activities has been a complicated exercise. However, systematically selecting, measuring, and analyzing the economic benefits derived from SRS programs can assist teams and leagues in refining existing SRS programs and choosing new ones. Effective measurement methods include periodic surveying of key stakeholders and monitoring stakeholder action. The attitudes of corporate partners can be solicited to determine the impact of SRS initiatives on sponsorship decisions. Media reports can be analyzed to determine which kinds of SRS programs are picked up and which are not. Fan input can be solicited to inform the actual development of social responsibility programs and to examine attitudes toward existing programs. It is likely that using stakeholder opinion and behavior research to refine social responsibility strategy can increase economic gains.

\footnotetext{
* Jason Chung, BCL/LLB, is a senior research scholar at New York University (NYU) Sports and Society; email: jason.chung@nyu.edu
} 
This paper, developed through literature review and interviews with senior leaders in the North American sports industry, will outline the challenges and benefits of engaging in SRS systematically and posit an approach to measuring SRS outcomes that balances organizational goals with social goals. By undertaking such an approach, as well as consistently evaluating those efforts via mixed methodological tools, the sport industry can create a more transparent and appealing covenant with key stakeholders and become the leading industry for effective and engaged efforts to "do good."

\section{Approaching SRS Systematically}

The range of activities that might fall under the rubric of SRS is broad. Defining what social responsibility in sports means, and developing categories within SRS, can inform how SRS efforts are structured. While all professional sports entities might agree that SRS is about "doing the right thing," there is no consensus on boundaries or scope.

The undefined SRS landscape creates a "burden of opportunity" for sports leagues. League motivations for choosing specific SRS initiatives include, but are not limited to, responding to current controversies and events, the personal interests of senior leadership, targeting the interests of potential new fan demographics, and the desire to satisfy marketing partners. Some efforts are created and refined within team or league departments, and many are the result of corporations and nonprofits approaching with potential partnership ideas.

All interviewed stakeholders expressed interest in models for systematic selection and design of SRS engagement. Each team and league has capacity to develop and refine such a system driven by data collection and analysis. Implementing data-driven SRS can increase the positive community impact of each initiative, and can improve economic and political gains. Incorporating impact measurement policy into team and league operations, and requiring standards for proof of positive impact in contract relations between sport entities, nonprofits, and corporate sponsors, can provide benchmarks by which to compare future partnership decisions, and help ensure authentic programs that are actually helping improve society.

\section{Lesson from Corporate Social Responsibility: The Importance of Identifying Clear Motives}

Understanding the motives behind social responsibility activities can help frame the desired outcome and identify appropriate metrics to measure success. ${ }^{1}$ Borrowing from corporate social responsibility (CSR) literature, it is possible to classify the motivations for social responsibility efforts as: (1) economic, (2) political, (3) social, and (4) ethical. ${ }^{2}$

\footnotetext{
Elisabet Garriga \& Domènec Melé, Corporate Social Responsibility Theories: Mapping the Territory, 53 Journal of Business Ethics 51, 52 (2004).

${ }_{2}$ Id.
} 
The language of "doing the right thing" speaks to ethical motivations. This stems from two theories of moral philosophy, one of which is that individuals in positions of power should help those in need, ${ }^{3}$ and the other is that a business cannot exist but for the cooperation and consent of society. ${ }^{4}$ The moral arguments hold that as professional sports leagues gain power and resources made possible by the support of their communities, they owe society, especially the disadvantaged members, something in return. A global poll of respondents' attitudes towards SRS indicates a general public expectation that sports leagues should engage in social responsibility programs. ${ }^{5}$ When asked whether professional sport organizations have the obligation to be socially responsible, over $70 \%$ of respondents answered in the affirmative without significant variation according to gender, age, household income, marital status, level of education, or employment status. ${ }^{6}$

Political and social motivations are both about improving relationships. Social responsibility programs implemented with attention to the expressed interests of community governing bodies and the community itself can position leagues and teams favorably when they need support for decisions like building new venues or relocating. Economic motivations are the ways in which social responsibility programs are engineered to improve the business's bottom line. It is arguable that all motivations outside of the ethical-or doing "good"-relate at least indirectly back to increasing profit.

The delineation between motivations is not always clear. A league's ability to improve its political and social power or to increase profits through SRS efforts is, in theory, contingent on accountability to government and the public. If the league runs a program or partnership that serves society well, society will reward it with loyalty and respect, which can improve its business. In our interviews, at least one league explained that the public holds it accountable for having ethical motivations in ways that the public does not hold other businesses. Fans have also explained that they are wary of league-driven social responsibility programs, believing them to be profit-motivated, but could be convinced of their value if supported by evidence of impact. Accordingly, the public's trust is likely best earned by driving social responsibility efforts with the intention of creating positive social impact, and supporting this intention with program effectiveness data. Satisfaction of secondary motivations (i.e., benefitting the team or league's business) will almost certainly follow.

\footnotetext{
3 See Bernard Williams, Ethics and the Limits of Philosophy, 185-186 (Cambridge: Harvard, 1985).

4 See Craig Smith, Corporate Social Responsibility: Whether or How?, 45 California ManageMENT ReVIEW 52 (2003).

5 IPSOS, Going Beyond the Sport, Ipsos Socialogue, global poll conducted Oct. 2015. Data on file with authors.

${ }^{6}$ Id.
} 


\section{Levels or Type of Engagement}

Social responsibility efforts can be categorized according to the mode of engagement, the intended cause, and the intended beneficiaries. These categories can be used to choose the combination of efforts that best represent the character and goals of particular leagues and teams, and that will have the greatest positive impact. This reflects a general shift away from merely looking at social responsibility as it benefits the firm and balancing that with an eye toward benefits to targeted stakeholders. ${ }^{7}$

Many sports leagues and teams feel a need to engage in a variety of initiatives with unique goals and constituencies in order to create meaningful social change. For instance, many leagues have a signature cancer-focused campaign: the National Football League (NFL) focuses on breast cancer awareness, the National Hockey League (NHL) has Hockey Fights Cancer, Major League Baseball (MLB) has Stand Up To Cancer, and Major League Soccer (MLS) has Soccer Kicks Cancer. In addition to raising funds, leagues partner with advocacy and nonprofit organizations to increase awareness through in-game promotions, advertisements during broadcasts, ad reads by announcers during broadcasts, and online presence.

Generally speaking, we have identified the following most common modes of professional sport organization SRS engagement:

- Charitable donations (philanthropy)

- Fundraisers (i.e., "half of tonight's concession proceeds go toward...")

- Athlete and employee participation in community programs

- Promotional television airtime for causes and/or partner organizations

- Social media promotion

- Program development for causes (e.g., improving literacy, improving youth education, improving health and socialization through youth sports)

- Internal league training programs (diversity, violence prevention, life skills, etc.)

- Internal wellness and safety programs

Modes of engagement can be chosen according to the strengths of the organization and tailored to the needs of the cause.

\section{Types of SRS and Resulting Benefits}

Conceptualizing categories of engagement can inform how to focus and diversify efforts. The highest order categories of SRS are (1) external and (2) internal activities. External social responsibility "promotes the pursuit of positive impacts

See Godfrey, supra note 33 at 709. 
on society (including economic) and the natural environment from corporate activities and operations." ${ }^{8}$ These activities aim to improve the constituencies and communities supporting teams and leagues, or other communities in need. Internal social responsibility, on the other hand, "focuses inside the organization: what can be done internally to improve the well-being of workforce, their lives and productivity as well as its impact on profitability and the bottom-line."

External and internal initiatives reflect and reinforce each other. Ostensibly, workforces benefit when they engage in external social responsibility programs, and employees that become safer and better citizens through internal programs have positive impacts on their communities. Surveyed public attitudes indicate an expectation that teams and leagues will engage in both internal and external programming. External SRS activities include but are not limited to the following:

- Efforts involving physical activity, such as fighting childhood obesity and building sports infrastructure in underserved areas

- Fighting racism, sexism, homophobia, and other forms of prejudice in society

- Efforts to combat poverty or improve employment opportunities in specific underserved communities

- Contributing to or partnering with nonprofit organizations that target individual and public health issues, such as fighting cancer, heart disease, malaria, and HIV

- Contributing to the community in which the organization is based through efforts to improve city infrastructure

- Efforts to address environmental issues such as pollution and global warming

- Efforts involving secondary education, such as going to university or trade school

- Supporting members of the United States military and military families

With regard to external SRS, a global poll shows that external efforts that best resonate with fans as authentic are those that benefit children, focus on health, are tied to the communities in which the teams and leagues operate, and relate to the sport sponsoring the effort..$^{10}$

The sheer amount of competition for attention in the sports world can sometimes drown out the positive impacts of SRS efforts. ${ }^{11}$ To effectively compete for attention in a crowded sports and media landscape, it is suggested that a more

\footnotetext{
8 Shame Mugova, Moono Mudenda, \& Paul Sachs, Corporate Social Responsibility in Challenging Times in Developing Countries, Corporate Social Responsibility in Times of Crisis, 207, 211, Springer (2017).

9 Id.

${ }_{10}$ See IPSOS, Social Responsibility Starts on the Field, Ipsos Socialogue, global poll conducted Oct. 2015. Data on file with authors.

11 NYU Team Owner Interview No. 1, 2015. Transcript on file with authors.
} 
coordinated or collective action among multiple sports teams and/or leagues might bring about greater social change and aggregate into larger impact. ${ }^{12} \mathrm{~A}$ cross-league or cross-team SRS partnership might allow organizations to combine marketing forces, achieve greater attention, and bring about greater social impact.

Internal SRS league activities include but are not limited to the following:

- Making sure athletes and other employees are as safe as possible

- Making sure athletes and other employees are trained in life skills and issues of social awareness such as domestic violence, financial planning, racial and religious sensitivity, education, family responsibility, and other issues

- Contributing to fighting racism, sexism, homophobia, and other forms of prejudice within the sport

- Promoting diversity within the sport

Internal social responsibility efforts can have far-reaching implications. Health and safety studies and regulation changes regarding concussions at the professional level have catalyzed efforts to protect youth and amateur athletes internationally. These improvements are reinforced by a global poll that suggests the public believes internal SRS efforts should focus on athlete and employee education and health. ${ }^{13}$ Anti-discrimination efforts have led to cultural milestones such as the first openly gay male professional athletes in the NBA and the MLS, and increasing minority and female participation in NASCAR. These events set precedents for inclusion at youth and amateur levels.

The external and internal categories listed can be modified to fit each league's and team's social responsibility profile, and can be used to identify how efforts are currently being divided.

\section{Addressing the Key Challenge to SRS: Measurement}

Leagues and teams know the importance of both internal and external SRS. They have committed significant resources to these programs and assembled capable staff to run and refine them. The development of league social responsibility activities appears to be driven by an instinctive blend of responding to current events and selecting from countless potential partners that approach with proposals. Programs are designed with attention to what seems to make sense for the organization-criteria include selecting activities that affect nearby communities, and that have a clear connection to the sport. These choices generally resonate with fans. But what makes a single SRS campaign successful? How can a league learn from a program that never gained traction? When does a team know that it is making significant contributions to society that also benefit its business?

\footnotetext{
12 NYU Team Owner Interview No. 2, 2015. Transcript on file with authors.

13 See IPSOS, Social Responsibility Starts on the Field, Ipsos Socialogue, global poll conducted Oct. 2015. Data on file with authors.
} 


\section{Why Is Measurement Important? The Growing Importance of Social Impact}

The sports industry faces an increasingly educated, skeptical, and socially concerned consumer base. The expectation that professional sports engage in social responsibility initiatives has solidified, which means that a sport organization's efforts to improve society that would have garnered significant media attention a decade ago now compete for attention with similar efforts across leagues and teams. It also means that missing an opportunity to engage prompted by something like an environmental disaster or engaging without complete transparency can negatively influence public perception. Research indicates that the public both expects social responsibility in sports and also distrusts the purity of sports leagues' social responsibility motives. A commitment to demonstrating the effectiveness of SRS programs can help earn the trust of fans, government, and sponsors. These commitments should be embodied in team and league policy and should be required in contracts between sport organizations, nonprofits, and industry partners.

Measurement of expenditure and impact are key to demonstrating SRS commitment to the public and can help track the value of a specific program. Focus group participants who felt that league SRS programs are attempts to make money also said that presenting effectiveness data would help convince them of a program's authenticity. For example, participants were more convinced of the value of a reading initiative that objectively explained it "raised literacy rates by $13 \%$ among children" than they were of a program that "opened children's imaginations and inspired them to read" without presenting impact data. ${ }^{14}$

Building impact-tracking methods into the cost of running an SRS program will ensure the availability of effectiveness data. Tools can also be used to track the extent to which such data influences stakeholder perceptions. Leagues are already tracking SRS resonance in social media (e.g., the number of unique tweets about a campaign). Minimal effort would be required to monitor correlations between the presentation of impact data and changes in campaign awareness. The value of such data to the public, sponsors, and government partners could also be solicited through periodic opinion surveys. This information could then be used to calculate each program's return on investment (ROI) in terms of fan resonance, media attention, sponsor interest, and political interest. Developing team and league policy that requires SRS measurement demonstrates commitment to transparency and ethical motivation.

\section{What Should We Measure?}

SRS is "the right thing to do" and theoretically makes business sense. SRS can motivate the workforce and increase its safety and loyalty, it can deepen connections with fans and sponsors, improve image in the media, and can help recruit new stakeholders. However, systems for tracking the social impacts of SRS programming and ROIs are necessary to translate these benefits from theoretical into empirical.

\footnotetext{
14 NYU Focus Groups hosted by Fondulas Strategic Research, LLC, Jan. 13, 2016, Chicago, Illinois. Transcripts on file with authors.
} 
The authors propose a common industry framework in order to evaluate individual SRS activities. The structure for measuring SRS should (1) weigh the various investments made by leagues against (2) the output and social impact created by the activity, and should (3) track ROIs.

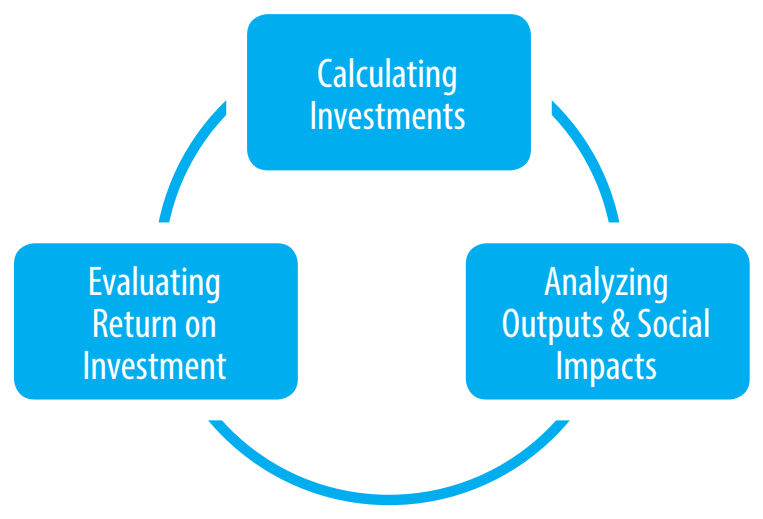

Figure 1. NYU Impact Tracking Model for Social Responsibility

Calculating investments allows the league to monitor the percent of its available social responsibility budget dedicated to any given effort, and the percent of its total budget allocated to social responsibility. In some situations, this information may also be valuable for public transparency. This measurement is relatively straightforward - money and time spent-and not contingent on the type of program being implemented. Analyzing outputs and social impacts demonstrates the effectiveness of the program in meeting its stated goal and is crucial for public transparency.

Methods for measuring social impact are heavily contingent on the type of program being implemented (e.g., changes in literacy rate, obesity level, employment, water quality). Actual social impact will often be difficult to measure. In these cases, "outputs" can be used as a proxy. For example, money allocated to cancer prevention may not directly translate to reduced cancer rate. Instead, outputs like the funding of specific research grants at specific institutions can be measured. These methods will require investment and careful planning. Evaluating ROI is for internal investigation as to whether the program confers business benefits. These measurements will be somewhat contingent on the program being implemented, but will always revolve around stakeholder response (e.g., fan consumption behavior, sponsorship renewal or acquisition).

It is likely that programs with significant social impact relevant to fan expectations (children, health, local community) that are adequately publicized will provide economic returns. Quantifying the correlations between investment, social impact, and returns will allow the program's implementer to make adjustments to future programs. For example, if investment was high but social impact is low, then funds and/or time were not used effectively. If the effort was carried out by a partner nonprofit, then this entity might need to adjust its action 
strategy or be dropped for a more effective organization. If social impact is high but return is low, then the publication strategy might need to be adjusted or the effort itself might not resonate with stakeholders.

Social responsibility is unlike consumer products and does not lend itself to easy measurement. Systems will take time to build and must be adjusted over time. The power of transparency and effectiveness data to sway sophisticated stakeholder opinions support the value of publicly committing to the development of such measurement systems. Ensuring the development of such systems can be aided by teams and leagues creating policy that require measurement and reporting of SRS impact at the executive level. A C-Suite that mandates regular data on the effects of its SRS programs demonstrates a culture of commitment. Industry partners can use measurement requirement clauses in contractual relationships to ensure their sport partners are committed to authentic initiatives, and to demonstrate their own such commitment to stakeholders.

\section{What Are the Appropriate Measurements at Each SRS Stage?}

Each of the aforementioned stages requires a different set of variables that must be measured. In the following sections, we begin to identify potential variables and measurements, which can be refined or expanded according to the specifics of individual programs.

\section{Calculating investments}

Most, if not all, leagues track the amount invested in their social responsibility programs. In some cases, these figures are already used to publicly demonstrate the level of commitment to a particular initiative. Pairing these figures with program impact data will likely increase influence on stakeholder perception. In addition, comparing these figures to social impact data and program resonance data will allow leagues to make adjustments to future investment strategies.

The investments made by leagues in SRS in some activities are easier to measure than others. For instance, charitable and philanthropic investments can largely be measured in straight dollar terms with the cost of employee participation calculable on an hourly or daily basis. On the other hand, with regard to promotional airtime offered to causes or partner organizations, leagues would have to summate different promotional activities during a telecast and assign them individual values. For instance, direct ad reads by announcers might be totalled up and assigned a value equivalent to the per-second cost for advertisers while promotional signage on the field of play can be benchmarked against costs charged for in-stadium advertising along the sidelines or sideboards. Similarly, with regard to athlete participation in SRS activities, a value would have to be assigned to the participation of individual players taking into account several factors such as the difficulty of compelling such athletes to participate and how much attention they can bring the SRS activity.

\section{Analyzing outputs and social impacts}

Measuring the impact of a social responsibility program requires understanding the program's long-term goals and setting short-term targets. Social concerns rarely have quick fixes, so measuring social impact strictly in terms of achieving 
Table 1. Common Types of SRS Engagement, and Relevant Resource Investments

\begin{tabular}{|c|c|c|}
\hline $\begin{array}{l}\text { Mode of SRS } \\
\text { Engagement }\end{array}$ & Focus & Calculable Investments \\
\hline $\begin{array}{l}\text { Charitable donations/ } \\
\text { philanthropy }\end{array}$ & External & $\begin{array}{l}\text { - Amount donated } \\
\text { - Number of hours spent on collection, coordination, and } \\
\text { marketing by FTE and PTE }\end{array}$ \\
\hline Fundraisers & External & $\begin{array}{l}\text { - Advertisement expenditure } \\
\text { - Creation of unique materials or goods } \\
\text { - Number of hours donated by employees }\end{array}$ \\
\hline $\begin{array}{l}\text { Athlete and employee } \\
\text { participation in community } \\
\text { programs }\end{array}$ & External & $\begin{array}{l}\text { - Number of hours donated by athletes and FTE and } \\
\text { PTE in organizing, performing, and marketing such } \\
\text { activities }\end{array}$ \\
\hline $\begin{array}{l}\text { Promotional airtime for causes } \\
\text { and/or partner organizations }\end{array}$ & External & $\begin{array}{l}\text { - Value of airtime donated to promotional causes and/or } \\
\text { partner organizations } \\
\text { - Number of hours spent by FTE and PTE in organizing, } \\
\text { performing, and marketing such activities }\end{array}$ \\
\hline $\begin{array}{l}\text { Program development for } \\
\text { causes }\end{array}$ & External & $\begin{array}{l}\text { - Direct financial investment made to establish, staff, } \\
\text { execute, and market program } \\
\text { - Number of hours spent by league FTE and PTE to } \\
\text { support program }\end{array}$ \\
\hline $\begin{array}{l}\text { Internal league training } \\
\text { programs }\end{array}$ & Internal & $\begin{array}{l}\text { - Cost of establishing processes and structural framework } \\
\text { for internal program } \\
\text { - Event costs of hosting workshops or symposia for } \\
\text { athletes and other employees } \\
\text { - Number of hours spent by FTE, PTE, and outside } \\
\text { consultants in conceiving and executing program } \\
\text { - Cost of temporary productivity lost if any internal } \\
\text { restructuring occurs }\end{array}$ \\
\hline $\begin{array}{l}\text { Internal wellness and safety } \\
\text { programs }\end{array}$ & Internal & $\begin{array}{l}\text { - Event costs of hosting workshops or symposia for } \\
\text { athletes and other employees } \\
\text { - Cost of equipment } \\
\text { - Number of hours spent by FTE, PTE, and outside } \\
\text { consultants in conceiving and executing } \\
\text { - Social capital used in negotiations with players' } \\
\text { associations in order to establish such demands on } \\
\text { athletes' time }\end{array}$ \\
\hline
\end{tabular}


long-term goals would provide no sense of progress. "Outputs," which can be defined as precursors to social impact, can serve as quantifiable targets toward achieving long-term goals. ${ }^{15}$

Measuring both outputs and long-term social impacts is necessary to assess the effectiveness of SRS efforts. Outputs can help establish the reach and visibility of the SRS program until social impact data is available. As a hypothetical, the NBA runs the "Read to Achieve" program to promote literacy among children. In that example, one output might be the number of children who participated in the program while the social impact would be a rise in youth literacy rates in the participating communities.

Another example is the World Wrestling Entertainment's (WWE) association with Susan G. Komen in their joint "Rise Above Cancer" program, designed for "bringing awareness and helping us fund lifesaving research, and support to families living with breast cancer who need our help today." 16 As a part of that program, WWE donated "20 percent of the retail sales price of each Rise Above Cancer piece sold online and at WWE live events October 5-26, 2015." WWE Superstars and Divas also wore such branded gear at WWE events in addition to airing multiple public service announcements dedicated to the cause. ${ }^{17}$ The WWE also provided an easy donate option of $\$ 1, \$ 5$, or $\$ 10$ to Komen upon checkout on purchases from http://WWEShop.com. ${ }^{18}$

In this example, a possible output might include the number and size of grants awarded to specific cancer research teams. A clear social impact would be reduction in breast cancer resulting from treatments made possible by the grants. The distinction between output and social impact is not always clear. If this campaign provides transportation or treatment to families living with breast cancer, an important measurement might be the number who received such benefits.

Measuring outputs and social impact includes identifying obstacles and limitations to effectiveness. At the time of writing this article, a review of the Susan G. Komen foundation on the Charity Navigator website, a service dedicated to cataloguing the effectiveness of charitable giving, only rates the organization as $2 / 4$ stars with regard to overall impact and financial performance, ${ }^{19}$ which translates to "Meets or nearly meets industry standards but underperforms most charities in its Cause." ${ }^{20}$ One reason for this rating is compensation to top exec-

\footnotetext{
15 See Rahim Kanani, How To Measure Social Impact: New Research And Insights, ForBes (March 15 2014). Available at http://www.forbes.com/sites/rahimkanani/2014/03/15/how-to-measure-social-impact-new-research-and-insights/.

16 WWE, WWE Goes Pink with Susan G Komen, W Community (2015). Available at https://community.wwe.com/hope/news/wwe-goes-pink-susan-g-komen-2015.

17 WWE Partnership Page, Susan G Komen. Available at http://ww5.komen.org/WWE/.

18 See WWE, supra note 58.

19 Charity Navigator, Susan G Komen for the Cure. Available at http://www.charitynavigator.org/ index.cfm?bay=search. summary\&orgid=4509 (last accessed Dec. 15 2017).

20 Charity Navigator, What do our ratings mean? Available at http://www.charitynavigator.org/ index.cfm?bay=content.view\&cpid=43 (last accessed Dec. 15 2017).
} 
utives, which has been criticized as excessive and "way outside the norm" for a charity of its size. ${ }^{21}$

In assessing the comparison between investment and social impact, leagues might question whether other charities with higher ratings such as the National Breast Cancer Foundation, Inc. might be more effective. Decisions like this based on ensuring greater effectiveness are also valuable points for publicity.

\section{Evaluating program resonance}

Sports leagues are not charities. It is reasonable for leagues to examine SRS initiatives' benefits for their businesses. The extent to which an SRS program resonates with fans, employees, sponsors, and other partners is a useful indication of positive effects for the business. In some cases, direct economic gains from SRS programs can also be measured.

Table 2. Methods for Measuring Stakeholder Resonance

\begin{tabular}{cl}
\hline Categories of Program Resonance & \multicolumn{1}{c}{ Methods for Measurement } \\
\hline Fan & $\begin{array}{l}\text { survey; social media monitoring; } \\
\text { qualitative interviews; focus groups }\end{array}$ \\
Employee & $\begin{array}{l}\text { survey; social media monitoring; } \\
\text { qualitative interviews; focus groups }\end{array}$ \\
Nonprofit & survey; qualitative interviews \\
Government & qualitative interview \\
Sponsor & survey; qualitative interview \\
Media & survey; monitoring news outlets \\
Public & survey; social media monitoring; \\
& qualitative interviews; focus groups \\
\hline
\end{tabular}

The importance of measuring program resonance or other ROIs may vary according to the scope of the SRS program. Investments in SRS often constitute a significant proportion of team or league resources, which indicates that social responsibility is integral to league identity, but such investments must be tied to business returns for the league to remain viable. Conversely, SRS programs that require less resources are less consequential for business survival, but may also be of less value to society and fall short of stakeholder expectations. Systematic

\footnotetext{
${ }_{21}$ See Lisa Meyers \& Talesha Reynolds, Susan Komen CEO's Salary Draws Fire as Donations Drop, Races Are Canceled, NBC News (June 10, 2013). Available at http://investigations.nbcnews.

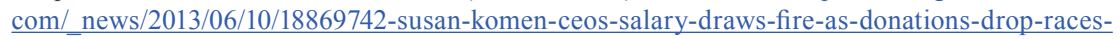
are-canceled (explaining that founder and former CEO Nancy Brinker earned \$684,000 in 2013. With a new CEO in place, Brinker's annual salary was set at $\$ 390,000$ in a new role as Founder and Chair, Global Strategy. For FYI 03/2014, partial year compensation for the new CEO, Judith Solerno was already at \$209,120 while Brinker earned \$480,784).
} 
measurement will allow for the refinement of programs that provide greater social ROI, and provide greater business returns that can then be directed back to SRS initiatives.

\section{Conclusion}

Social responsibility is a collective goal. It is a commitment to helping those in need. Professional sport organizations, by virtue of their visibility, resources, and integration in communities, have great power to improve public welfare. Committing to social responsibility in sports means creating space outside the competition that defines the games and the business, and committing to improvement through careful evaluation of preceding efforts. Beyond the great SRS work already being performed by most U.S. teams and leagues, including the development of social responsibility departments to oversee such efforts, this commitment can further be reflected and reinforced by league policy requiring detailed monitoring of input, social impact, fan resonance, and ROI. Sports entities and industry sponsors can provide their nonprofit partners with the additional resources necessary to better demonstrate achievement of their missions through research-based measurement and can hold them accountable for doing so via contract. If professional sport organizations can share and refine SRS measurement techniques, and collaborate on SRS initiatives, they can affect significant social change, and set a precedent for other industries. 